\title{
Milk yield, oxytocin and $\beta$-endorphin gradually normalize during repeated milking in unfamiliar surroundings
}

\author{
BY RUPERT M. BRUCKMAIER, HANS-ULRICH PFEILSTICKER \\ AND JÜRG W. BLUM \\ Institut für Tierzucht der Universität Bern, CH-3012 Bern, Schweiz
}

(Received 25 May 1995 and accepted for publication 18 October 1995)

\begin{abstract}
Summary. For six successive milkings, six dairy cows were relocated immediately before milking to an unfamiliar operating theatre, a procedure previously shown to inhibit oxytocin release and milk ejection. Two control milkings were performed in familiar surroundings. After milk flow had ceased, two i.v. injections of 1 i.u. oxytocin were given to remove the remaining milk. Milk flow was recorded continuously and blood samples were taken every minute during milking and $10 \mathrm{~min}$ after milking. During the first milking in unfamiliar surroundings, no oxytocin was released. Thereby, only $13 \%$ of the total milk yield, the cisternal milk, was available and the alveolar milk fraction could only be removed after injection of oxytocin. During subsequent relocations oxytocin release steadily increased toward the control level, although the timing of oxytocin release remained delayed as compared with controls. However, the milk fraction available before oxytocin injection increased with increasing number of removals, following an asymptotic approach to control levels. The concentrations of $\beta$-endorphin, cortisol (and perhaps also of prolactin) gradually declined with the number of times the animal was moved to unfamiliar surroundings, i.e. hormone concentrations gradually adjusted to control level. During milking, concentrations of prolactin and cortisol increased, while $\beta$-endorphin concentrations decreased (except for the first relocation). We conclude that milkingrelated oxytocin release and therefore milk ejection adapted gradually to repeated relocations to unfamiliar surroundings. This adaptation was inversely related to $\beta$-endorphin concentrations, so it is possible that oxytocin release was suppressed by high circulating $\beta$-endorphin concentrations.
\end{abstract}

Milk removal can be disturbed under various conditions and can principally be divided into peripheral and/or central inhibition of milk ejection (Bruckmaier \& Blum, 1994).

Peripheral inhibition is characterized by catecholamine action at the level of the mammary gland, even if oxytocin (OT) is released normally during milking (Lefcourt \& Akers, 1984; Gorewit \& Aromando, 1985; Roets \& Peeters, 1985; Blum et al. 1989 ; Bruckmaier et al. 1991). Peripheral inhibition of milk ejection is due to $\alpha$-adrenergic receptor stimulation (Blum et al. 1989; Bruckmaier et al. 1991, 1992, 1993; Hammon et al. 1994).

Central inhibition of milk ejection due to no or reduced release of OT can be totally abolished by administration of exogenous OT in physiological amounts and is found in primiparous parturient cows (Bruckmaier et al. 1992), in cows during peak 
oestrus (Bruckmaier \& Blum, 1994) and in cows milked in unfamiliar surroundings (Bruckmaier et al. 1993, 1994a,b).

In a previous investigation, milk yield was dramatically diminished and OT concentration remained basal when cows were displaced immediately before milking, while plasma concentrations of prolactin, cortisol and $\beta$-endorphin were elevated (Bruckmaier et al. 1993). A transient reduction of milk yield of dairy cows was demonstrated after relocation to new housing systems (Varner et al. 1983).

The goal of this work was to examine if and how cows adapt to unfamiliar surroundings if they are relocated repeatedly before milking.

\section{Animals}

MATERIALS AND METHODS

The six experimental cows (three Simmental $\times$ Red Holstein, three Swiss Braunvieh $\times$ Brown Swiss) in weeks 10-33 of their second to third lactation belonged to the herd of the Swiss Federal Research Station for Animal Production, Posieux. In their familiar barn the cows were housed in tie stalls in groups of 24 animals and fed on maize silage, hay and concentrates according to their individual production levels.

\section{Materials and experimental procedure}

Experimental milkings were performed during routine milking times from 06.00 to 08.00 and from 16.00 to 18.00 at a vacuum level of $45 \mathrm{kPa}$, a $65: 35$ pulsator ratio and a pulsation rate of 60 cycles/min, using 'Harmony' clusters (Alfa Laval, S-147 21 Tumba, Sweden). Milk flow was continuously recorded with a strain gauge system and conveyed to a strip chart recorder as described by Schams et al. (1984). At $6 \mathrm{~h}$ before the first milking, indwelling catheters were inserted into the left jugular vein of all cows for blood sample collection and OT injection.

The cows were milked at six successive milkings in the operating theatre of the research station. The first relocation was either at morning (three cows) or at evening milking (three cows). Each time the cows were relocated immediately before milking. In addition, two control milkings were performed in the familiar barn. Milking was started after a 1 min manual teat stimulation (Fig. 1). After milk flow had ceased 1 i.u. OT (a physiological dose) was injected intravenously (Fig. 1). The udder was completely emptied by a second OT injection (1 i.u., i.v.) and machine stripping (Fig. 1).

\section{Laboratory evaluations}

Blood samples $(10 \mathrm{ml})$ were collected via a catheter at $1 \mathrm{~min}$ intervals from $2 \mathrm{~min}$ before the start of milking until the end of milking. An additional sample was taken at $10 \mathrm{~min}$ after milking. The blood samples were treated with heparin anticoagulant (50 USP units $/ \mathrm{ml}$ blood), cooled on ice and centrifuged immediately after the experiment at $1500 \mathrm{~g}$ for $20 \mathrm{~min}$. The plasma was stored at $-20^{\circ} \mathrm{C}$ until determination of hormone concentrations. Plasma OT concentrations were determined by radioimmunoassay after extraction with $\mathrm{C}_{18}$ cartridges (Waters SEPPAK C $_{18}$, Millipore Corporation, Milford, MA 01757, USA) as described in detail by Schams (1983). Recovery (50-70\%) was dependent on the amount of extracted plasma $(0.5-1.0 \mathrm{ml})$. OT for iodination and standard was purchased from Bachem Feinchemikalien AG (CH-4416 Bubendorf). ${ }^{125} \mathrm{I}$ was used to label OT using chloramine $\mathrm{T}$. The reaction was stopped with sodium pyrosulphite and the ${ }^{125} \mathrm{I}$ labelled products were purified on a Sephadex C50 column (Pharmacia LKB 

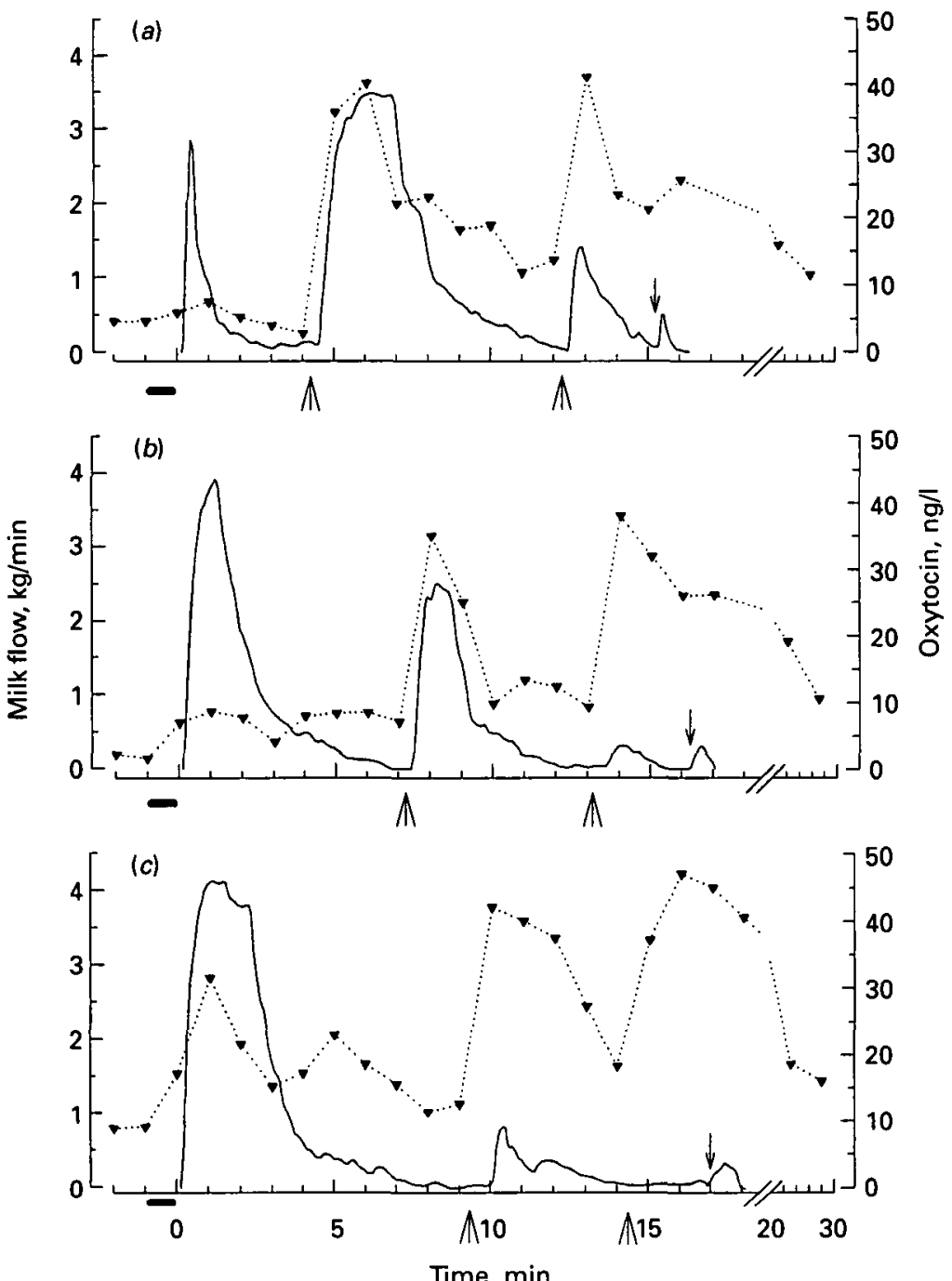

Fig. 1. $\boldsymbol{\nabla}$, Concentration of oxytocin and _ـ, milk flow rate in one cow before, during and after milking in $(a)$ unfamiliar surroundings (first relocation), $(b)$ unfamiliar surroundings (third relocation) and $(c)$ its familiar barn. - , Teat stimulation; 0 , start of milking; $\mathbb{A}$, i.v. injection of 1 i.u. oxytocin; $\downarrow$, stripping.

Biotechnology AB, S-751 82 Uppsala, Sweden). The antiserum against OT, which was raised in a rabbit, was highly specific for OT and did not cross react with vasopressin and other pituitary hormones (Robinson, 1980). The standard curve ranged from 1.5 to $200 \mathrm{ng} / \mathrm{l}$; the intercept at $50 \%$ relative binding was at $25 \mathrm{ng} / \mathrm{l}$. The assay allowed us to measure $\geqslant 1.0 \mathrm{ng} / \mathrm{l}$ if $1 \mathrm{ml}$ plasma was extracted. Intra-assay and interassay CV were 10 and $12 \%$ respectively. The assay procedure was carried out according to Schams (1983). Prolactin, cortisol and $\beta$-endorphin were determined by radioimmunoassay as described previously by Bruckmaier et al. (1992).

\section{Evaluation of results and statistical analyses}

For statistical evaluation, seven phases were defined during milking time as shown in Table 1. OT and prolactin were analysed in all blood samples. The OT and prolactin concentrations are presented as mean values for phases 1, 2, 3 and 5 and 


\section{Table 1. Phases during the course of the experiment}

\begin{tabular}{cl} 
Phase & \multicolumn{1}{c}{ Definition } \\
1 & Time before stimulation was started (after relocation) \\
2 & First 2 min of milking \\
3 & Between 2 min of milking and the first oxytocin injection \\
4 & Last 2 min before the first oxytocin injection \\
5 & First 2 min after the first oxytocin injection \\
6 & Last 2 min before the end of milking \\
7 & At 10 min after the end of milking
\end{tabular}

phases 1, 4, 6 and 7 respectively. For cortisol and $\beta$-endorphin, only one blood sample each was analysed for phases $1,4,6$ and 7 and phases 1,4 and 7 respectively.

Changes during milking compared with premilking baseline values were tested for significance by paired $t$ test $(P<0.05)$. Within-phase differences between relocations and control were tested for significance by ANOVA $(P<0.05)$ using the SAS program package, release 6.08 (SAS, 1990).

\section{RESULTS}

\section{Milk yields and milking characteristics}

Total milk yields were similar in unfamiliar $(12 \cdot 8 \pm 0 \cdot 6 \mathrm{~kg})$ and familiar $(12.7 \pm 0.8 \mathrm{~kg})$ surroundings. Unless indicated otherwise, all values are given as means \pm SEM.

The milk fraction spontaneously received after prestimulation and machine onset rapidly increased from the first to the second and third relocations (Table 2, Fig. 1). Thereafter it increased more slowly until the sixth removal, when it reached approximately control levels (Table 2). Consequently, the milk fraction ejected in response to the first $\mathrm{OT}$ injection was continuously decreasing from the first to the sixth relocation and control. The small last milk fraction $(4.5 \pm 0.4 \%)$, collected after the second OT injection, was not significantly different between relocations and control milkings.

Peak flow rate of the milk fraction received spontaneously after machine onset greatly increased from the first to the second and then less markedly up to the sixth relocation to reach control values $(1.42 \pm 0.54,3 \cdot 21 \pm 0.50,3.82 \pm 0.31$ and $3.93 \pm 0.24 \mathrm{~kg} / \mathrm{min}$ respectively), i.e. in an asymptotic manner. This peak flow rate was negatively correlated with the peak flow rate in response to the first $\mathrm{O}^{\mathrm{T}}$ injection $(3 \cdot 58 \pm 0 \cdot 14,3 \cdot 46 \pm 0 \cdot 29,1 \cdot 56 \pm 0 \cdot 33$ and $1 \cdot 11 \pm 0 \cdot 25 \mathrm{~kg} / \mathrm{min}$ respectively; $r=0 \cdot 39$, $P<0.05$ ).

The lag time from the first OT injection until the start of milk flow increased with decreasing amounts of milk remaining in the udder after removal of the spontaneous milk fraction. Thus, lag time had already returned to control levels by the third relocation $(27 \pm 2,29 \pm 1,35 \pm 4$ and $34 \pm 2 \mathrm{~s}$ at the first, second and third relocation and at control milkings respectively).

\section{Oxytocin concentrations}

Premilking basal plasma OT concentrations (phase 1) were similar during all relocations and in control milkings $(3 \cdot 4 \pm 0 \cdot 4$ and $5 \cdot 2 \pm 1 \cdot 2 \mathrm{ng} / \mathrm{l}$ respectively). The increment of plasma OT concentration during the first 2 min of milking (phase 2) was significantly smaller in unfamiliar than in familiar surroundings and was not 
Table 2. Oxytocin concentration changes during the first 2 min of milking (phase 2) and from 2 min until oxytocin was injected the first time (phase 3) and spontaneously obtained milk fraction

\begin{tabular}{|c|c|c|c|}
\hline \multicolumn{4}{|c|}{ (Values are means $\pm \mathrm{SEM}$ for $n=6$ ) } \\
\hline $\begin{array}{c}\text { Relocation } \\
\text { no. }\end{array}$ & $\begin{array}{c}\text { Changes in } \\
\text { oxytocin, } \\
\text { phase } 2 \\
\text { ng/l }\end{array}$ & $\begin{array}{c}\text { Changes in } \\
\text { oxytocin, } \\
\text { phase } 3 \text {, } \\
\text { ng/l }\end{array}$ & $\begin{array}{l}\text { Spontaneous milk } \\
\text { fraction, } \% \\
\text { of total }\end{array}$ \\
\hline 1 & $0 \cdot 6 \pm 0 \cdot 6^{\mathrm{a}}$ & $-0 \cdot 4 \pm 0 \cdot 1^{\mathrm{a}}$ & $13 \pm 5^{\mathrm{a}}$ \\
\hline 2 & $0 \cdot 6 \pm 0 \cdot 6^{\mathrm{a}}$ & $1 \cdot 5 \pm 0 \cdot 8^{n}$ & $42 \pm 9^{b}$ \\
\hline 3 & $2 \cdot 0 \pm 1 \cdot 0^{\mathrm{a}}$ & $3 \cdot 4 \pm 2 \cdot 1^{\mathrm{ab}}$ & $70 \pm 6^{c}$ \\
\hline 4 & $0.5 \pm 0.9^{\mathrm{a}}$ & $4 \cdot 6 \pm 2 \cdot 0^{\mathrm{ab}}$ & $73 \pm 7^{\mathrm{c}}$ \\
\hline 5 & $2 \cdot 9 \pm 1 \cdot 7^{\mathrm{a}}$ & $4 \cdot 0 \pm 2 \cdot 2^{\mathrm{ab}}$ & $77 \pm 7^{\mathrm{c}}$ \\
\hline 6 & $1 \cdot 6 \pm 1 \cdot 2^{\mathrm{a}}$ & $5 \cdot 1 \pm 2 \cdot 6^{\mathrm{ab}}$ & $83 \pm 4^{\mathrm{c}}$ \\
\hline Control $\dagger$ & $8 \cdot 0 \pm 3 \cdot 5^{b}$ & $8 \cdot 3 \pm 2 \cdot 6^{b}$ & $86 \pm 2^{c}$ \\
\hline
\end{tabular}

$a, b, e$ Values in the same column without a common superscript letter were significantly different: $P<0 \cdot 05$. $\dagger$ Control, familiar surroundings.

significantly changed with repeated relocations (Table 2, Fig. 1). Even after $2 \mathrm{~min}$ milking (phase 3), the plasma OT concentration remained low during the first relocation. However, the OT rise during milking increased progressively from the first to the sixth relocation, although it never reached the values found in control milkings during the period of the experiment (Table 2). After the first OT injection (phase 5) the plasma OT concentration increased to a high level in all milkings but was lower in the first three than in the latter three relocations. During the last three relocations OT levels reached those in control milkings $(25 \cdot 6 \pm 2 \cdot 0,35 \cdot 4 \pm 4 \cdot 6$, $39 \cdot 3 \pm 5 \cdot 4 \mathrm{ng} / \mathrm{l}$ respectively).

\section{Prolactin concentrations}

Plasma prolactin concentrations before milking (phase 1) were numerically but not significantly higher in relocations than in controls (Table 3). Values decreased from the first to the sixth relocation and finally reached values similar to those measured in control milkings. During milking (phases 4 and 6), plasma prolactin concentrations increased; however, this was significant only in familiar surroundings. At $10 \mathrm{~min}$ after the end of milking (phase 7) plasma prolactin concentrations remained the same in the first two relocations, but fell slightly in all other treatments.

\section{Cortisol concentrations}

Basal cortisol concentrations (phase 1) were elevated in the first two relocations (Table 3). During milking (phases 4 and 6), plasma cortisol concentrations were significantly higher in all milkings compared with controls, but the changes themselves were not significant. The increase was highest in the first relocation, and fell towards the sixth relocation to control values. Thus, cortisol concentrations at the end of milking (phase 6) decreased significantly from the first to the sixth relocation and control. At $10 \mathrm{~min}$ after milking (phase 7) plasma cortisol concentration was still numerically increased from the first to the fourth relocation but decreased slightly from the fifth to the sixth relocation and to values of control milkings; however, these changes were not statistically significant. 


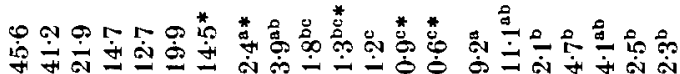
$+1+1+1+1+1+1+1+1+1+1+1+1+1+1+1+1+1+1+1+1$

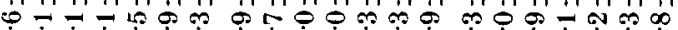

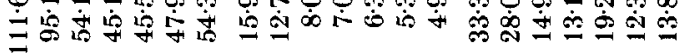




\section{$\beta$-Endorphin concentrations}

Basal concentrations of $\beta$-endorphin (phase 1) were elevated in relocations as compared with controls (Table 3). During milking (phase 4), concentrations of $\beta$ endorphin decreased significantly from the first to the six th relocation and to control values. During and after milking (phases 4 and 7$), \beta$-endorphin concentrations were starting to decrease again in all relocations except the first, where $\beta$-endorphin concentrations increased, although not significantly, further during milking. During control milkings $\beta$-endorphin did not change.

\section{DISCUSSION}

Basal concentrations (phase 1) of OT were similar at all milkings in unfamiliar and familiar surroundings and in the range found previously (Schams et al. 1984; Mayer et al. 1991 ; Bruckmaier et al. 1993).

In response to prestimulation and machine milking, OT was released as expected in the familiar barn, obviously causing complete alveolar milk ejection (phases 2 and 3; Schams et al. 1984; Mayer et al. 1991; Bruckmaier et al. 1993), and resulting in removal of the main milk fraction before $\mathrm{OT}$ was injected. In contrast, and in accordance with our previous investigations (Bruckmaier et al. 1993), after the first relocation OT concentrations remained at baseline levels during milking (phases 2 and 3), milk ejection did not occur and only a small amount of milk was removed which was comparable to the cisternal milk fractions found in other investigations (Bruckmaier et al. 1994a; Knight et al. 1994).

The OT release was delayed in all relocations; i.e. a more prolonged stimulus had to be applied before OT increased. However, after the second minute of milking until OT was injected, OT was gradually and slowly increasing from the first to the sixth relocation. OT concentrations remained below control level during the duration of the experiment, although the milk flow curves and milk yields were already normalized at the sixth relocation. This confirms the theory that after a certain threshold level any additional OT released has no further effect on milk removal (Schams et al. 1984).

It has been shown previously that OT is normally released during the entire milking procedure (Mayer et al. 1984; Schams et al. 1984), and continuously elevated concentrations of $\mathrm{OT}$ above a threshold level are necessary for complete milk removal (Bruckmaier et al. 1994b). Obviously, the OT release during early relocations was not sufficient to eject the entire alveolar milk fraction. Either the threshold level was exceeded only for a short period or the OT was not really above the threshold level, inducing only partial alveolar contraction and milk ejection. However, a high percentage of milk could be removed after the third relocation, although the OT increase was delayed and concentrations reached only $\sim 50 \%$ of the control level. This finding provides additional support for the existence of a threshold level of O'T. However, partial alveolar milk ejection seemed to be induced even if OT concentration was below this threshold level. Partial milk ejection was previously observed in response to the brief stimulus from teat cannulation, which caused a transient OT release (Mayer et al. 1991).

After the first OT injection (phase 5), the OT concentration was significantly elevated in all milkings and sufficiently high to eject almost all retained milk. The lag time from the first OT injection until the start of milk flow was therefore not influenced by an endogenous OT release. However, in accordance with previous 
results (Bruckmaier et al. 1994b) inc lag time depended directly on the amount of milk still remaining in the udder. Because this fraction was highest at the first relocation and consequently lag time was shortest, any effect of emotional stress on the responsiveness of the mammary gland to OT is very unlikely. Furthermore, the complete milk yield was not influenced by relocations and was similar in familiar and unfamiliar surroundings. Peripheral inhibition of milk removal, which was shown to occur after catecholamine administration with simultaneous normal OT release (Blum et al. 1989; Bruckmaier et al. 1991), could therefore be excluded. In addition, in the first relocation peak flow rate after the injection of OT was already comparable to the milk flow rate before OT injection in the familiar barn. Furthermore, we have shown that plasma concentrations of adrenaline and noradrenaline were always in the normal range under our experimental conditions (R. M. Bruckmaier \& J. W. Blum, unpublished results), indicating that inhibition of milk ejection was solely due to disturbed $\mathrm{OT}$ release.

Elevated concentrations of cortisol and $\beta$-endorphin and perhaps also of prolactin indicate that relocations to unfamiliar surroundings provoked a considerable emotional stress. Elevated cortisol concentrations have previously been reported in cows after relocation (Varner et al. 1983), during transportation (Bremel \& Gangwer, 1978 ) and during isolation from companion animals (Willett \& Erb, 1972) and are considered to be a stress reaction. During the course of milking (phases 1 and 4), concentrations of cortisol were increasing in all milkings as in previous experiments (Bruckmaier et al. 1993), i.e. cortisol increased in a normal manner during milking even if the basal concentration was already elevated. Adrenocorticotropin (ACTH), the releasing factor for cortisol, and $\beta$-endorphin are derived from a common precursor in the pituitary (Eipper \& Mains, 1980) and were shown to be released concomitantly in stressed rats (Guillemain et al. 1977). Furthermore, the administration of opioid peptides lowers the release of cortisol in cows through negative feedback (Nanda et al. 1992). The simultaneously elevated concentrations of $\beta$ endorphin and cortisol in unfamiliar surroundings during milking indicate a similar common regulation of $\mathrm{ACTH}$ and $\beta$-endorphin release in cows.

Until OT was injected the $\beta$-endorphin concentrations were falling except for the first relocation. Interestingly, the OT concentration during milking increased only if the $\beta$-endorphin concentration had decreased during milking. Consistent with this, OT was not released during the first 2 min of milking for all relocations. When $\beta$ endorphin increased during milking (first relocation), the OT concentration remained basal. While an inhibitory effect of cortisol on OT release in cows is unlikely (Mayer $\&$ Lefcourt, 1987), elevated circulating $\beta$-endorphin was shown to suppress OT release in rats (Bicknell et al. 1988) and mice (Haldar \& Bade, 1981). Therefore, increased circulating $\beta$-endorphin after relocation to unfamiliar surroundings was possibly responsible for deficient OT release.

It has been shown that endogenous $\beta$-endorphin modulates prolactin release in several species (Barb et al. 1991) and that the administration of the opioid antagonist naloxone influences prolactin concentrations in ewes, calves and cows (Gregg et al. 1986; Johnson et al. 1989). It is likely that elevated concentrations of $\beta$-endorphin were in part responsible for the (not significantly) higher values of prolactin in unfamiliar surroundings.

In conclusion, while the concentrations of $\beta$-endorphin, cortisol and perhaps also prolactin were gradually declining with increasing relocation number, the milkingrelated OT release was enhanced. Thus, OT and prolactin release were probably modulated by high $\beta$-endorphin concentrations. In emotionally stressed animals 
milk yields without OT injection were significantly smaller and time until OT was released was prolonged.

This study was supported by Alfa Laval Agri, Sursee (Switzerland) and Tumba (Sweden). The antiserum against oxytocin was kindly donated by Dr I. C. A. F. Robinson, Laboratory for Endocrine Physiology and Pharmacology, National Institute of Medical Research, Mill Hill, London, NW7 1AA, UK. The expert assistance of Mrs C. Morel and Mrs Y. Zbinden for the hormone assays is greatly appreciated.

\section{REFERENCES}

Barb, C. R., Kraeling, R. R. \& Rampack, G. B. 1991 Opioid modulation of gonadotropin and prolactin secretion in domestic farm animals. Domestic Animal Endocrinology 8 15-27

Bicknell, R. J., Zhao, B.-G., Chapman, C., Heavens, R. P. \& Sirinathsinghu, D. J. S. 1988 Opioid inhibition of secretion from oxytocin and vasopressin nerve terminals following selective depletion of neurohypophysial catecholamines. Neuroscience Letters 93 281-286

Blum, J. W., SChams, D. \& Bruch mater, R. 1989 Catecholamines, oxytocin and milk removal in dairy cows. Journal of Dairy Research 56 167-177

Bremel, R. D. \& Gangwer, M. I. 1978 Effect of adrenocorticotropin injection and stress on milk cortisol content. Journal of Dairy Science 61 1103-1108

Bruckmaier, R. M. \& Blum, J. W. 1994 Central and peripheral inhibition of milk ejection in dairy cows. Proceedings of the International Symposium: Prospects for Future Dairying: A Challenge for Science and Industry. Alfa Laval Agri, Tumba, Sweden

Bruckmaier, R. M., Mayer, H. \& Schams, D. 1991 Effects of $\alpha$-and $\beta$-adrenergic agonists on intramammary pressure and milk flow in dairy cows. Journal of Dairy Research 58 411-419

Bruckinater, R. M., Rothenanger, E. \& Blum, J. W. $1994 a$ Measurement of mammary gland cistern size and determination of the cisternal milk fraction in dairy cows. Milchwissenschaft $49543-546$

Bruckmaier, R. M., Schams, D. \& Blum, J. W. 1992 Aetiology of disturbed milk ejection in parturient primiparous cows. Journal of Dairy Research 59 479-489

Brtckmaier, R, M., Schans, D. \& Blum, J. W. 1993 Milk removal in familiar and unfamiliar surroundings: concentrations of oxytocin, prolactin, cortisol and $\beta$-endorphin. Journal of Dairy Research $60449-456$

Bruckmaler, R. M., Schans, D. \& Blum, J. W. $1994 b$ Continuously elevated concentrations of oxytocin are necessary for complete milk removal in dairy cows. Journal of Dairy Research 61 323-334

EIPPER, B. A. \& MalNS, R. E. 1980 Structure and biosynthesis of pro-adrenocorticotropin/endorphin and related peptides. Endocrine Revieus 1 1-27

Gorewit, R. C. \& Aromando, M. C. 1985 Mechanisms involved in the adrenaline-induced blockade of milk ejection in dairy cattle. Proceedings of the Society for Experimental Biology and Medicine $180340-347$

Grege, D. W., Moss, G. E., Hudoens, R. E. \& Malven, P. V. 1986 Endogenous opioid modulation of luteinizing hormone and prolactin secretion in postpartum ewes and cows. Journal of Animal Science 63 $838-847$

Gullemain, R., Vargo, T., Rossier, J., Minick, S., Ling, N., Rivier, C., Vale, W. \& Bloom, F. 1977 $\beta$-Endorphin and adrenocorticotropin are secreted concomitantly by the pituitary gland. Science 197 $1367-1369$

HALDAR, J. \& BADE, V. 1981 Involvement of opioid peptides in the inhibition of oxytocin release by heat stress in lactating mice. Proceedings of the Society for Experimental Biology and Medicine 168 10-14

Hamon, H. M., Bruckmaler, R. M., Honegger, U. E. \& BLum, J. W. 1994 Distribution and density of $\alpha$ and $\beta$-adrenergic receptor binding sites in the bovine mammary gland. Journal of Dairy Research 61 47-57

Johnson, D. W., Barnes, M. A., Akers, R. M., Pearson, R. E. \& Gwazdauskas, F. C. 1989 Increased prolactin secretion following exogenous opioid administration in Holstein dairy calves occurs by a centrally mediated mechanism. Journal of Dairy Science 67 Suppl. 1 Abstr. no. 870

KNIGht, C. H., HIRST, D. \& DEwhurst, R. J. 1994 Milk accumulation and distribution in the bovine udder during the interval between milkings. Journal of Dairy Research 61 167-177

Lefcourt, A. M. \& Akers, R. M. 1984 Small increases in peripheral noradrenaline inhibit the milk-ejection response by means of a peripheral mechanism. Journal of Endocrinology 100 337-344

Mayer, H., Bruckmaier, R. \& Schams, D. 1991 Lactational changes in oxytocin release, intramammary pressure and milking characteristics in dairy cows. Journal of Dairy Research 58 159-169

MAYER, H. \& LeFCOURT, A. M. 1987 Failure of cortisol injected prior to milking to inhibit milk ejection in dairy cattle. Journal of Dairy Research 54 173-177

Mayer, H., Schams, D., Worstorff, H. \& Prokopp, A. 1984 Secretion of oxytocin and milk removal as affected by milking cows with and without manual stimulation. Journal of Endocrinology 103 355-361

NANDA, A.S., DoBSon, H.\& WARD, W. R. 1992 Opioid modulation of the hypothalamo-pituitary-adrenal axis in dairy cows. Domestic Animal Endocrinology 9 181-186 
Robinson, I. C. A. F. 1980 The development and evaluation of a sensitive and specific radioimmunoassay for oxytocin in unextracted plasma. Journal of Immunoassay $1323-347$

Roets, E. \& Peeters, G. 1985 Identification and characterization of ${ }^{3} \mathrm{H}$-prazosin binding of $\alpha_{1}$-adrenoreceptors in bovine teat muscles. Archives Internationales de Pharmacodynamie et de Thérapie $275189-198$

SAS 1990 SAS Users' Guide: Statistics. Cary, NC: SAS Institute

Schams, D. 1983 Oxytocin determination by radioimmunoassay. III. Improvement to subpicogram sensitivity and application to blood levels in cyclic cattle. Acta Endocrinologica 103 180-183

Schams, D., Mayer, H., Prokopp, A. \& Worstorff, H. 1984 Oxytocin secretion during milking in dairy cows with regard to the variation and importance of a threshold level for milk removal. Journal of Endocrinology $102337-343$

Varner, M. A., Johnson, B. H., BritT, J. H., McDaniel, B. T. \& Mochrie, R. D. 1983 Influence of herd relocation upon production and endocrine traits of dairy cows. Journal of Dairy Science $66466-474$

WILLETT, L. B. \& ERB, R. E. 1972 Short time changes in plasma corticoids in dairy cattle. Journal of Animal Science 34 103-111 